\title{
Greetings from the University President \\ On the Occasion of The Journal of the Rutgers University Libraries' Seventy-fifth Anniversary
}

\section{Dear Readers:}

The first sentence of the first edition of this fine journal came from the typewriter of President Robert C. Clothier: "All friends of the University," he wrote, "have the interest of the University Library at heart." The journal had been established in order to raise awareness of and financial support for the impressive collection of volumessome 300,000 in 1937. Over the ensuing seventy-five years, the library's collection of volumes has grown more than tenfold as Rutgers itself made the transition to a major public research institution and the official state university of New Jersey.

Today, just a few years from our $250^{\text {th }}$ anniversary in 2016, Rutgers is poised to expand its mission once again, as Governor Christie has signed legislation that will integrate into Rutgers nearly all academic units of the University of Medicine and Dentistry of New Jersey. Once our governing boards approve this plan, the scope of the university will grow substantially, adding an academic medical center and creating synergies in the health sciences and many other academic areas. The expanded university will create new challenges for our libraries in serving our growing community of scholarsand I have no doubt that we will rise to the challenge. Rutgers takes pride in claiming one of the finest research library systems in the nation, and incorporating the resources of the UMDNJ libraries will further enhance and expand our system's strength.

\section{I congratulate Vice President for Information Services and} University Librarian Marianne Gaunt and Editor Robert G. Sewell, and I salute all those who have contributed to The Journal of the Rutgers University Libraries over the years. Their work has enriched Rutgers scholarship and brought well-deserved attention to the rich 
history and resources of the Libraries, the university, and the state. Best of all, with the digitization of the Journal, readers of a new generation can view afresh the excellent writings of these Rutgers scholars.

Happy anniversary!

Sincerely,

Robert L. Barchi

University President 